\title{
Farklı Aktivatör Ve Ham Madde Değişkenlerinin Geopolimer Hamurun Basınç Dayanımına Etkisinin İncelenmesi
}

\author{
Enes Ekinci ${ }^{1}$, İbrahim Türkmen ${ }^{2}$ \\ 1* İnönü Üniversitesi, Mühendislik Fakültesi, İnşaat Mühendisliği Bölümü, Malatya, Türkiye, (ORCID: 0000-0001-7669-887X), enes.ekinci@inonu.edu.tr \\ 2* İnönü Üniversitesi, Mühendislik Fakültesi, İnşaat Mühendisliği Bölümü, Malatya, Türkiye, (ORCID: 0000-0001-7560-0535), ibrahim.turkmen@ @inonu.edu.tr
}

(2nd International Conference on Access to Recent Advances in Engineering and Digitalization (ARACONF)-10-12 March 2021)

(DOI: $10.31590 /$ ejosat.903895)

ATIF/REFERENCE: Ekinci, E. \& Türkmen, İ. (2021). Farklı Aktivatör Ve Ham Madde Değişkenlerinin Geopolimer Hamurun Basınç Dayanımına Etkisinin İncelenmesi. Avrupa Bilim ve Teknoloji Dergisi, (24), 169-175.

\section{Öz}

Bu çalışmada geopolimer hamurların basınç dayanımı özelliklerine kullanılan ham madde ve alkali aktivatör özelliklerinin etkileri incelenmiştir. Geopolimer hamur numunelerinde ham madde olarak F sınıfı uçucu kül (UK) ve yüksek firın cürufu (YFC) kullanılmıştır. Birbiri içerisinde değişik oranlarda ikamesi sağlanan (100U, 80U-20Y, 60U-40Y, 40U-60Y, 20U-80Y, 100Y) ham maddeler, $\mathrm{Na}_{2} \mathrm{SiO}_{3}$ ve $\mathrm{NaOH}(8,10,12$ ve $14 \mathrm{M})$ kullanılarak aktive edilmiştir. Tüm örnekler, deney gününe kadar laboratuvar koşullarında kür edilmiştir. Üretilen 180 adet geopolimer hamur numunelerin 7 ve 28. günlerdeki basınç dayanımı değerleri incelenmiştir. Sonuçlar, kullanılan ham madde ve alkali aktivatör özelliklerinin değişmesiyle birlikte basınç dayanımı değerlerinin büyük oranda değiştiğini göstermiştir. YFC ikame oranının artmasıyla birlikte, basınç dayanımı değerlerinde ciddi artışlar gözlenmiştir. Ayrıca, F sınıfı UK kullanılarak üretilecek geopolimer örneklerin laboratuvar şartlarında yüksek dayanım özelliklerine sahip olmaları içi ısıl küre ihtiyaç duyduğu gözlenmiştir. Kullanılan ham madde tipinden bağımsız olarak, $\mathrm{Na}_{2} \mathrm{SiO}_{3}$ ile aktive edilen tüm örnekler, 28 günlük nihai dayanımının \% 85'den fazlasını ilk 7 gün içerisinde kazanmıştır. Öte yandan, maksimum basınç dayanımının elde edilmesi için kullanılması gereken optimum $\mathrm{NaOH}$ konsantrasyonunun, bağlayıcı içeriğine bağlı olarak değişiklik gösterdiği saptanmıştır.

Anahtar Kelimeler: Uçucu kül, yüksek fırın cürufu, geopolimer, kür, basınç dayanımı.

\section{Investigation of the Effect of Different Activator and Raw Material Variables on Compressive Strength of Geopolymer Paste}

\begin{abstract}
In this study, the effects of the raw material and alkali activator properties on the compressive strength properties of geopolymer pastes were investigated. Class F fly ash (FA) and blast furnace slag (S) were used as raw materials in geopolymer paste samples. The raw materials (100U, 80U-20Y, 60U-40Y, 40U-60Y, 20U-80Y, 100Y) were activated using $\mathrm{Na}_{2} \mathrm{SiO}_{3}$ and $\mathrm{NaOH}(8,10,12$ and $14 \mathrm{M}$ ). All samples were cured under laboratory conditions until the test day. The compressive strength values of geopolymer paste samples on the 7 and 28th days were examined. The results showed that with the change of raw material and alkali activator properties, the compressive strength values changed significantly. With the increase in the substitution rate of S, significant increases were observed in the compressive strength values. In addition, it was observed that geopolymer samples produced using class F FA need high temperature curing to have superior strength properties. Regardless of the type of raw material used, all samples activated with $\mathrm{Na}_{2} \mathrm{SiO}_{3}$ gained more than $85 \%$ of their 28-day ultimate strength in the first 7 days. On the other hand, it was determined that the optimum $\mathrm{NaOH}$ concentration that should be used to obtain the maximum compressive strength varies depending on the binder charecteristics.
\end{abstract}

Keywords: Fly ash, blast furnace slag, geopolymer, curing, compressive strength 


\section{Giriş}

İnşaat sektöründe vazgeçilmez bir yapı malzemesi olarak görülen çimento, son yıllarda artan kentleşme ve endüstriyel faaliyetler nedeniyle gittikçe yükselen bir kullanım kapasitesine sahip olmaktadır. 2014 yılında, dünyada yıllık 4 milyar ton çimento üretimi olduğu [1] ve dünya çapında çimento üretiminin yıllık \% 9 oranında artış gösterdiği bilinmektedir [2]. Mehta ve Monterio, (2006) tarafından yapılan çalışmada, 1 ton çimento üretimi için doğaya yaklaşık 1 ton $\mathrm{CO}_{2}$ gazı salındığını belirtilmiştir [3]. Benzer şekilde, beton üretiminden kaynaklanan $\mathrm{CO}_{2}$ gazı emisyonlarının yaklaşık \%74-81'inin çimento üretiminden kaynaklandığı ve çimento üretimi işleminin tüm endüstri faaliyetlerinin açığa çıkardığı $\mathrm{CO}_{2}$ gazı emisyonlarının yaklaşık \%5-7'lik bir bölümünü kapsadığg belirtilmiştir [4-6]. $\mathrm{CO}_{2}$ gazı emisyonlarının sebep olduğu sera gazı etkisi, güneş ışınlarının uzay boşluğuna yansımasını engellediğinden yeryüzünün sahip olduğu ortalama sıcaklığı yükseltmektedir [7]. Küresel 1sınma olarak adlandırılan bu süreç sonrasında, dünya ortalama sıcaklığının $1.4-5,3{ }^{\circ} \mathrm{C}$ arasında artacağı, artan sıcaklık nedeniyle deniz seviyesinde 8 ila $88 \mathrm{~cm}$ arasında yükselmeler olacağı ve dünyanın mevcut yapısında geri dönüşü olmayacak şekilde ciddi bozulmalar meydana geleceği öngörülmektedir [8].

Öte yandan, termik santraller ve demir-çelik tesisleri faaliyetleri sonucunda yan ürün olarak ortaya çıkan uçucu kül, yüksek firın cürufu vb. atık malzemelerin depolanması, taşınması ve bertaraf edilmesi gibi işlemler de ciddi ekonomik sorunlara ve verimli tarım arazilerinin işgal edilmesine yol açmaktadır $[9,10]$.

Tüm bu sorunlar göz önüne alındığında, çimento üretiminden kaynaklanan sorunları engellemenin yanında, yan ürün olarak açığa çıkan atık malzemelerin yeniden değerlendirilmesi de çevre kirliliği ve ekonomik bir üretim açısından hayati bir önem taşımaktadır. Ayrıca verimli bir ekonomik kalkınmanın, enerji kaynaklarını son derece etkin bir şekilde kullanmayla mümkün olacağının altı çizilmelidir [7]. Tam da bu noktada, geleneksel Portland çimentosuna en uygun alternatif olarak geopolimer malzemelerin varlığından bahsetmek gerekir. Alüminosilikat bazlı atık malzemeler ile (yüksek fırın cürufu, uçucu kül, silis dumanı vb.) alkali aktivatörler arasında meydana gelen kimyasal reaksiyonlar sonucunda oluşan geopolimer bağlayıcılar; çevre dostu olması, üretimi aşamasında gereken düşük maliyeti ve atık malzemelerin yeniden değerlendirilmesi nedeniyle Portland çimentosunun yerini alma potansiyeline sahiptirler $[11,12]$. İlk olarak 1970'lerde bahsedilen geopolimerler, amorf veya yar1 kristal bir yapıya sahip olan yeni bir malzeme sinifi olarak tanımlanmaktadır [13]. Geopolimerizasyon reaksiyonu alkalinitesi yüksek ortamlarda, alümino-silikat oksitler ile alkali çözeltiler arasında gerçekleşen bir reaksiyon olup, Si-O-Al bağlarını içeren üç boyutlu polimer zincirlerin oluşumunu sağlamaktadır [14]. Geopolimer bağlayıcılar, yapısal bütünlüğe ulaşmak amacıyla farklı reaksiyonlar gösterdiklerinden, geleneksel Portland çimentosu kullanılarak üretilen yap1 malzemelerine nazaran önemli ölçüde değişik performanslara sahiptirler. Geleneksel çimentonun reaksiyonu yerine silis ve alümin öncüllerinin polikondensasyonu olayını yüksek alkali ortamlarda gerçekleştirirler [15]. Benzer şekilde Yuan vd., (2016) tarafindan yapılan çalışmada geopolimerizasyon işlemi kısaca çözünmeyi takip eden yeniden düzenleme, yoğunlaştırma ve katılaşma işlemleri olarak tanımlanmıştır [16].
$\mathrm{Bu}$ çalışmada, geopolimer hamur örneklerin basınç dayanımı özellikleri üzerine ham madde ve aktivatör değişkenlerinin etkileri incelenmiştir. UK ve YFC' nin belirli oranlarda ikamesi sağlanarak hazırlanan ham maddeler, $\mathrm{Na}_{2} \mathrm{SiO}_{3}$ ve farklı molaritelerde $\mathrm{NaOH}$ kullanılarak aktive edilmiştir. Deney sonuçları, geopolimer örneklerin basınç dayanımlarında ham madde ve aktivatör karakteristiklerinin ciddi etkileri olduğunu göstermiştir.

\section{Materyal ve Metot}

\subsection{Materyal}

$\mathrm{Bu}$ çalışmada, geopolimer hamurların üretiminde bağlayıcı madde olarak yüksek firın cürufu (YFC) ve F sınıfı uçucu kül (UK) kullanılmıştır. Kullanılan ham maddelerin kimyasal özellikleri Tablo 1'de, SEM görüntüleri ise Şekil 1'de verilmiştir. Uçucu kül, Ekton İnşaat ve Yapı Fabrikasından temin edilmiş, yüksek firın cürufu ise Karçimsa firmasından temin edilmiştir.

Tablo 1. Kullanılan ham maddelerin kimyasal bileşimleri

\begin{tabular}{ccc} 
Bileşen, $(\%)$ & UK & YFC \\
\hline $\mathrm{SiO}_{2}$ & 63,04 & 32,47 \\
$\mathrm{Al}_{2} \mathrm{O}_{3}$ & 21,63 & 9,94 \\
$\mathrm{Fe}_{2} \mathrm{O}_{3}$ & 6,77 & 1,25 \\
$\mathrm{CaO}$ & 1,07 & 32,45 \\
$\mathrm{Na}_{2} \mathrm{O}$ & 2,79 & 0,31 \\
$\mathrm{MgO}$ & - & 9,31 \\
$\mathrm{Cr}_{2} \mathrm{O}_{3}$ & - & - \\
$\mathrm{SO}_{3}$ & 0,1 & 0,82 \\
$\mathrm{~S}^{-2}$ & - & 0,33 \\
$\mathrm{~K}_{2} \mathrm{O}$ & - & 0,85 \\
$\mathrm{TiO}_{2}$ & - & 1,16 \\
$\mathrm{Mn}_{2} \mathrm{O}_{3}$ & - & 3,51 \\
$\mathrm{CI}^{-}$ & - & 0,015
\end{tabular}

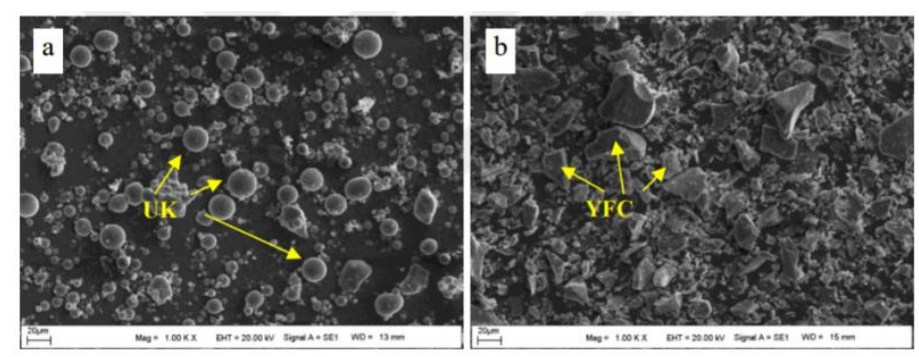

Şekil 1. Uçucu kül ve yüksek firın cürufunun SEM görüntüsü [17]

Çalışma boyunca alkali aktivatör olarak $\mathrm{NaOH}$ ve $\mathrm{Na}_{2} \mathrm{SiO}_{3}$ kullanılmıştır. Kullanılan alkali aktivatörlerin özellikleri Tablo 2'de verilmiştir. 
Tablo 2. Aktivatörlerin fiziksel ve kimyasal özellikleri

\begin{tabular}{lll}
\multicolumn{1}{c}{ Özellikler } & $\mathrm{NaOH}$ & $\mathrm{Na}_{2} \mathrm{SiO}_{3}$ \\
\hline $\mathrm{Mol}$ Kütlesi, (g/mol) & 40,00 & 122,06 \\
$\mathrm{Renk}$ & Beyaz & Beyaz \\
$\mathrm{Fe}_{2} \mathrm{O}_{3}$ & 6,77 & 1,25 \\
$\mathrm{pH}$ & $13-14$ & - \\
$\mathrm{Bağ} 1$ Yoğunluk, $\left(\mathrm{g} / \mathrm{cm}^{3}\right)$ & 2,13 & 1,38 \\
$\mathrm{Na}_{2} \mathrm{O}$ İçeriği, (\%) & - & 8,9 \\
$\mathrm{SiO}_{2}$ İçeriği, (\%) & - & 28,7 \\
$\mathrm{H}_{2} \mathrm{O}$ İçeriği, $(\%)$ & - & 64,8
\end{tabular}

\subsection{Metot}

Çalışmada bağlayıcı olarak UK ve YFC değişik oranlarda $(\% 0,20,40,60,80$ ve 100$)$ kullanılmıştır. Alkali aktivatör olarak 4 değişik molaritede $\mathrm{NaOH}(8,10,12$ ve $14 \mathrm{M})$ ve $\mathrm{Na}_{2} \mathrm{SiO}_{3}$ kullanılmıştır. NaOH çözeltileri, dökümden 24 saat önce hazırlanmış ve döküm anına kadar oda sıcaklığında bekletilmiştir [18-20]. Alkali sıvı/bağlayıcı oranı, $\mathrm{NaOH}$ ile aktivasyon metodunda $0,3, \mathrm{Na}_{2} \mathrm{SiO}_{3}$ ile aktivasyonda ise 0,35 olarak sabit tutulmuştur. Aktivasyon değişkenlerine göre 5 farklı grupta toplanan toplam 30 farklı karışım serisi Tablo 3 'te verilmiştir. Alkali solüsyonlar ile ham maddelerin karıştırılma işlemine 5 dakika boyunca devam edilmiş ve daha sonra taze geopolimer hamur numuneleri $50 * 50 * 50 \mathrm{~mm}$ boyutlarındaki çelik kalıplara yerleştirilmiştir. Döküm işlemi tamamlanan örnekler dökümden 48 saat sonra kalıplardan çıkarılmıştır. Toplamda 5 farklı aktivasyon yöntemi ve 6 farklı bağlayıcı içeriği olmak üzere 30 grup halinde dökümü tamamlanmış numuneler, 7 ve 28. günlerde basınç dayanımı testlerine tabi tutulmuştur. Geopolimer hamur numunelerinin basınç dayanımları ASTM C 109 standardına uygun bir şekilde yapılmıştır[21].

Tablo 3. Geopolimer hamur numunelerin karışım parametreleri

\begin{tabular}{|c|c|c|c|c|c|c|}
\hline \multirow{2}{*}{ Grup No } & \multirow{2}{*}{ Karışım } & \multicolumn{2}{|c|}{ Bağlayıcı } & \multicolumn{2}{|c|}{ Aktivatör } & \multirow{2}{*}{$\begin{array}{c}\text { Alkali/bağlayıcı } \\
\text { oranı }\end{array}$} \\
\hline & & UK, (\%) & YFC, (\%) & $\mathrm{NaOH},(\mathrm{M})$ & $\mathrm{Na}_{2} \mathrm{SiO}_{3}$ & \\
\hline \multirow{6}{*}{ I } & $100 \mathrm{U}$ & 100 & - & \multirow{6}{*}{8} & \multirow{6}{*}{-} & \multirow{6}{*}{0,3} \\
\hline & $80 \mathrm{U}-20 \mathrm{Y}$ & 80 & 20 & & & \\
\hline & $60 \mathrm{U}-40 \mathrm{Y}$ & 60 & 40 & & & \\
\hline & $40 \mathrm{U}-60 \mathrm{Y}$ & 40 & 60 & & & \\
\hline & $20 \mathrm{U}-80 \mathrm{Y}$ & 20 & 80 & & & \\
\hline & $100 \mathrm{Y}$ & - & 100 & & & \\
\hline \multirow{6}{*}{ II } & $100 \mathrm{U}$ & 100 & - & \multirow{6}{*}{10} & \multirow{6}{*}{-} & \multirow{6}{*}{0,3} \\
\hline & $80 \mathrm{U}-20 \mathrm{Y}$ & 80 & 20 & & & \\
\hline & $60 \mathrm{U}-40 \mathrm{Y}$ & 60 & 40 & & & \\
\hline & 40U-60Y & 40 & 60 & & & \\
\hline & $20 \mathrm{U}-80 \mathrm{Y}$ & 20 & 80 & & & \\
\hline & $100 \mathrm{Y}$ & - & 100 & & & \\
\hline \multirow{6}{*}{ III } & $100 \mathrm{U}$ & 100 & - & \multirow{6}{*}{12} & \multirow{6}{*}{-} & \multirow{6}{*}{0,3} \\
\hline & $80 \mathrm{U}-20 \mathrm{Y}$ & 80 & 20 & & & \\
\hline & $60 \mathrm{U}-40 \mathrm{Y}$ & 60 & 40 & & & \\
\hline & 40U-60Y & 40 & 60 & & & \\
\hline & $20 \mathrm{U}-80 \mathrm{Y}$ & 20 & 80 & & & \\
\hline & $100 \mathrm{Y}$ & - & 100 & & & \\
\hline \multirow{6}{*}{ IV } & $100 \mathrm{U}$ & 100 & - & \multirow{6}{*}{14} & \multirow{6}{*}{ - } & \multirow{6}{*}{0,3} \\
\hline & $80 \mathrm{U}-20 \mathrm{Y}$ & 80 & 20 & & & \\
\hline & $60 \mathrm{U}-40 \mathrm{Y}$ & 60 & 40 & & & \\
\hline & $40 \mathrm{U}-60 \mathrm{Y}$ & 40 & 60 & & & \\
\hline & $20 \mathrm{U}-80 \mathrm{Y}$ & 20 & 80 & & & \\
\hline & $100 \mathrm{Y}$ & - & 100 & & & \\
\hline \multirow{6}{*}{ V } & $100 \mathrm{U}$ & 100 & - & \multirow{6}{*}{-} & \multirow{6}{*}{$\mathrm{Na}_{2} \mathrm{SiO}_{3}$} & \multirow{6}{*}{0,35} \\
\hline & $80 \mathrm{U}-20 \mathrm{Y}$ & 80 & 20 & & & \\
\hline & $60 \mathrm{U}-40 \mathrm{Y}$ & 60 & 40 & & & \\
\hline & $40 \mathrm{U}-60 \mathrm{Y}$ & 40 & 60 & & & \\
\hline & 20U-80Y & 20 & 80 & & & \\
\hline & $100 \mathrm{Y}$ & - & 100 & & & \\
\hline
\end{tabular}




\section{Araştırma Sonuçları ve Tartışma}

\subsection{Geopolimer hamur numunelerin basınç dayanımı}

\subsubsection{Geopolimer hamur numunelerinin basinç dayanımına alkali aktivatör etkisi}

Dört farklı $\mathrm{NaOH}$ konsantrasyonu ve $\mathrm{Na}_{2} \mathrm{SiO}_{3}$ olmak üzere, toplam beş farklı aktivasyon yöntemi ile aktive edilen geopolimer hamur numunelerin 7 ve 28 günlük basınç dayanımı değerleri incelenmiştir. Ham madde olarak \%100 uçucu kül (UK) kullanılan geopolimer hamur numuneleri, $\mathrm{NaOH}$ ile aktive edilmesi halinde, ilk 7 günde herhangi bir dayanım kazanamamıştır. Ancak, \%100 UK numunesinin $\mathrm{Na}_{2} \mathrm{SiO}_{3}$ ile aktive edilmesi sonucunda, 28 günlük basınç dayanımının yaklaşık \%88'i ilk 7 günde kazanılmıştır. Bu durum, F sınıfı UK kullanılarak üretilecek ve laboratuvar koşullarında kür edilecek geopolimer hamur örneklerinde erken dayanım kazanmak için $\mathrm{Na}_{2} \mathrm{SiO}_{3}$ kullanımının gerekli olduğunu göstermektedir. Benzer şekilde, $80 \mathrm{U}-20 \mathrm{Y}$ karışımı ile üretilen ve $\mathrm{NaOH}$ kullanılarak aktive edilen örneklerde de ilk 7 günde dikkate değer bir dayanım kazanımı elde edilememiştir. Ancak, $\mathrm{NaOH}$ konsantrasyonun artması, 80U-20Y karışımı ile hazırlanan örneklerde ilk 7 günde daha fazla dayanıma yol açmıştır. Bu durum, yüksek alkali koşulların nispeten daha fazla erken dayanıma yol açtı̆̆ını göstermiştir. Ayrıca, YFC kullanım oranının en çok $\% 60$ oranında olduğu; 100U, 80U-20Y, 60U$40 \mathrm{Y}$ ve $40 \mathrm{U}-60 \mathrm{Y}$ örneklerinde ise $\mathrm{Na}_{2} \mathrm{SiO}_{3}$ ile aktivasyon yönteminin ilk 7 günde yüksek basınç dayanımı değerlerine yol açttğı görülmüştür. Şekil 3, 28 günlük basınç dayanımı değerleri üzerinde aktivatör tip ve konsantrasyonunun ciddi bir etkisi olduğunu göstermektedir. Şöyle ki, $100 \mathrm{U}$ numunelerinin 28 günlük basınç dayanımı değerlerinde, $\mathrm{NaOH}$ konsantrasyonunun 8 M'dan 14 M'a yükselmesi basınç dayanımını yaklaşık $\% 30$ oranında azaltmıştır. Benzer şekilde, $80 \mathrm{U}-20 \mathrm{Y}$ numunelerinde de en yüksek basınç dayanımı değerleri $8 \mathrm{M} \mathrm{NaOH}$ ile aktive edilen örneklerde gözlenmiştir. $60 \mathrm{U}-40 \mathrm{Y}$ ve $40 \mathrm{U}-60 \mathrm{Y}$ örneklerinde 28 günlük en yüksek basınç dayanımları $14 \mathrm{M} \mathrm{NaOH}$ ile aktive edilen numunelerde gözlenirken, $20 \mathrm{U}-80$ Y ve 100 Y örneklerinde ise maksimum basınç dayanımı $12 \mathrm{M} \mathrm{NaOH}$ aktivasyonu ile sağlanmıştır. Ham madde olarak UK ve YFC'nin kullanıldığı bir çalışmada $\mathrm{NaOH}$ konsantrasyonunun 8'den 16 M'a artmasıyla birlikte basınç dayanımı değerlerinde önemli iyileşmeler meydana geldiği gözlenmiştir [22]. Ancak bazı araştırmacılar ise, yüksek $\mathrm{NaOH}$ konsantrasyonunun basınç dayanımını azalttığı yönünde bulgular elde etmişlerdir [23].

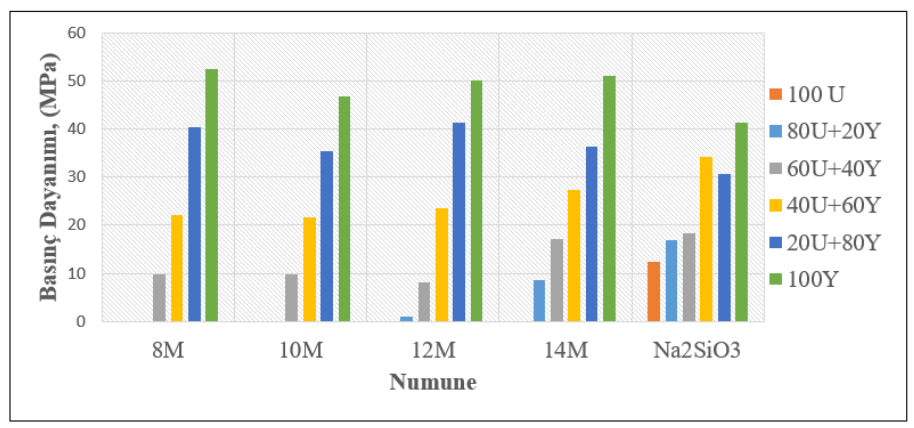

Şekil 2. Geopolimer hamur numunelerin 7 günlük basınç dayanımı

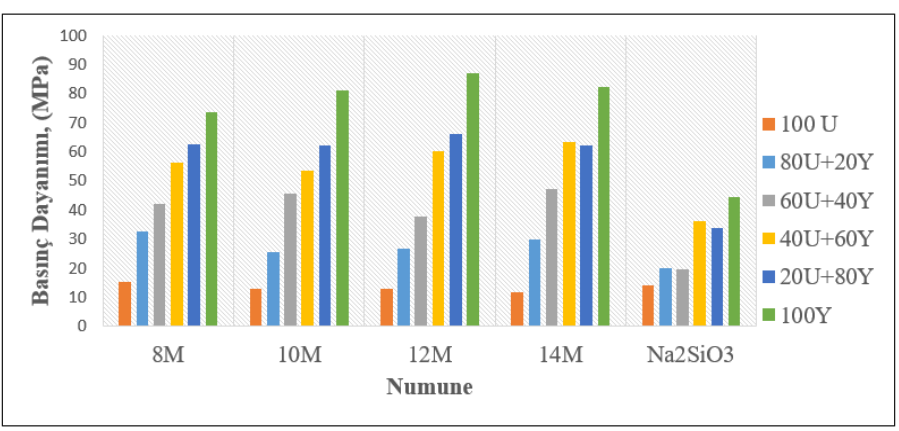

Şekil 3. Geopolimer hamur numunelerin 28 günlük basınç dayanımı

\subsubsection{Geopolimer hamur numunelerinin basınç dayanımına ham maddenin etkisi}

UK ve YFC kullanılarak 6 farklı bağlayıcı içeriğine sahip geopolimer hamurların 7 ve 28 günlük basınç dayanımı değerleri incelenmiştir. Şekil 4 ve 5, YFC ikame oranının artmasıyla birlikte geopolimer hamur numunelerinin 7 ve 28 günlük basınç dayanımlarında ciddi artışlar meydana geldiğini göstermektedir. $8 \mathrm{M} \mathrm{NaOH}$ kullanılarak aktive edilen geopolimer hamur numunelerinin 7 günlük basınç dayanımları incelendiğinde, YFC kullanım oranının 0'dan 100'e çıkmasıyla birlikte basınç dayanımının $0 \quad \mathrm{MPa}$ 'dan $52,45 \mathrm{MPa}$ değerine çıktığ görülmektedir. $\mathrm{Bu}$ durum, herhangi bir 1sıl kür uygulanmadan $\mathrm{F}$ sınıfı uçucu kül kullanılarak erken yüksek dayanıma sahip geopolimer kompozit üretiminin pek mümkün görülmediğini göstermektedir. Bir bağlayıcının hidrolik aktivitesinin bir ölçümü olarak nitelendirilen hidratasyon modülünün, daha hızlı ve yüksek dayanım kazanmaya işaret ettiği de bilinmektedir [24]. $\left[\left(\mathrm{CaO}+\mathrm{MgO}+\mathrm{Al}_{2} \mathrm{O}_{3}\right) / \mathrm{SiO}_{2}\right]$ formülüne sahip olan hidratasyon modülünün, çalışmada kullanılan UK ve YFC için sırasıyla 0,36 ve 1,59 olarak elde edilmesi, basınç dayanımı sonuçlarını doğrular niteliktedir. Benzer şekilde, Abhilash vd., tarafindan yapılan çalışmada, YFC'nin UK'ya ikame oranının artmasıyla birlikte basınç dayanımı değerlerinde ciddi artışlar gözlenmiştir [25]. Öte yandan, yüksek oranlarda YFC kullanılan geopolimer hamur numuneleri (100Y ve $80 \mathrm{Y}-20 \mathrm{U})$ dişında, en yüksek basınç dayanımı sonuçlarının $\mathrm{Na}_{2} \mathrm{SiO}_{3}$ ile aktivasyon sonucu elde edildiği görülmüştür. Sonuçlar, ayrıca aktivatör molaritesinin değişmesinin, UK kullanılarak üretilen geopolimer hamurların basınç dayanımlarının üzerinde çok büyük bir etkiye sahip olduğunu göstermiştir. $\mathrm{NaOH}$ molaritesinin değiştirilmesiyle 100-U esaslı geopolimer hamur numunelerinin 28 günlük basınç dayanımlarında yaklaşık \% 30'luk bir artış gözlenirken, $100 \mathrm{Y}$ esaslı geopolimer hamur numunelerinde bu artış ancak \% 18 düzeyinde olabilmiştir. Bu durum, Ravikumar vd., tarafından yapılan çalışmada elde edilen gözlemlerle paralellik göstermiştir [26]. 7 günlük en yüksek basınç dayanımı ise, $8 \mathrm{M} \mathrm{NaOH}$ ile aktive edilen $\% 100 \mathrm{Y}$ numunesinde gözlenmiştir. Benzer şekilde, UK bazlı geopolimer betonların dayanım kazanması için ısıl küre ihtiyaç duyduğunu, YFC kökenli geopolimer betonların ise ısıl kür olmadan laboratuvar şartlarında bekletilebileceğini gösteren bir çalışma mevcuttur [27]. 


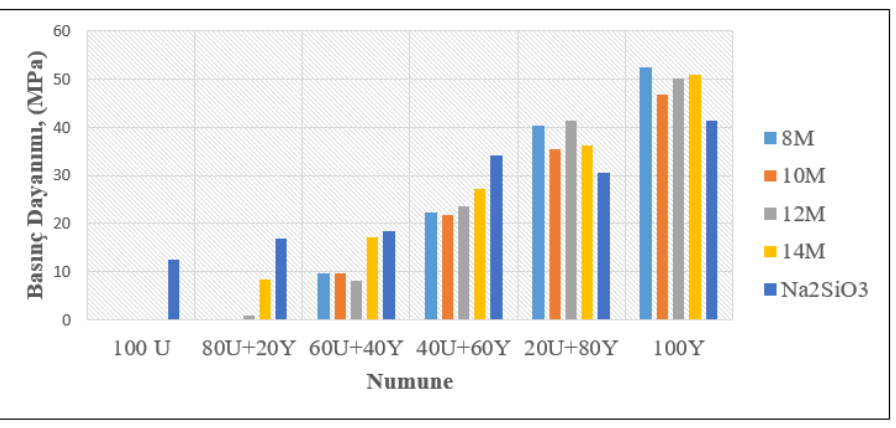

Şekil 4.7 günlük basınç dayanımına ham maddenin etkisi

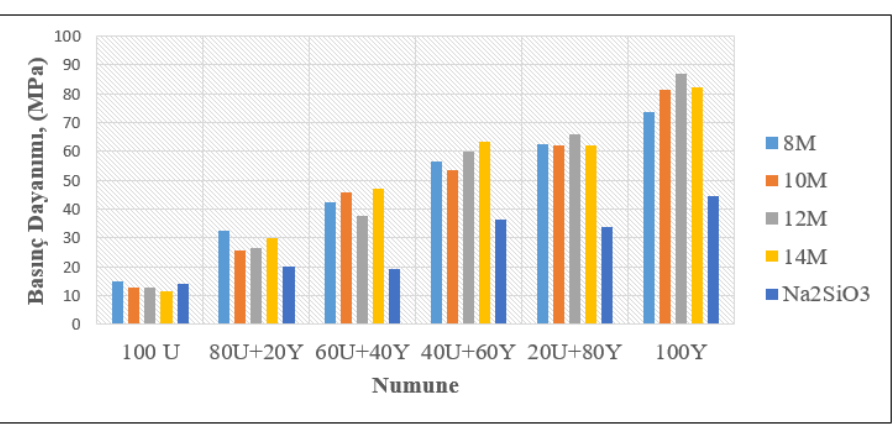

Şekil 5. 28 günlük basınç dayanımına ham maddenin etkisi

\subsubsection{Geopolimer hamur numunelerinin bekleme süresinin basinç dayanımına etkisi}

Şekil 6, geopolimer hamur numunelerinin bekleme sürelerinin basınç dayanımına etkisini göstermektedir. Tüm aktivasyon yöntemleri için, YFC oranının artmasıyla birlikte ilk 7 günde kazanılan dayanım oranları belirgin artışlar göstermiştir. Ayrıca, 8 ve $10 \mathrm{M} \mathrm{NaOH}$ ile aktive edilmiş $100 \mathrm{U}$ örneklerinin ilk 7 günde dayanım kazanmadığı gözlenmiştir. Sonuçlar, UK kullanılarak üretilen geopolimer hamurlarda, laboratuvar koşullarında yüksek erken dayanım kazanmak için $\mathrm{Na}_{2} \mathrm{SiO}_{3}$ ile aktivasyon metodunun uygulanması gerektiğini göstermektedir. Genel anlamda $\mathrm{NaOH}$ konsantrasyonunun artmasiyla birlikte ilk 7 günde dayanım kazanma oranı artış gösterse de, YFC ikame oranının yüksek olduğu numune gruplarında böyle bir bağıntı kurulamamıştır. Örneğin, $80 \mathrm{U}-20 \mathrm{Y}$ numune gruplarında, 8 ve 10 $\mathrm{M} \mathrm{NaOH}$ ile aktivasyon metodunda ilk 7 gün herhangi bir dayanım kazanma olmamasına rağmen, 12 ve $14 \mathrm{M} \mathrm{NaOH}$ ile aktivasyon işleminde sırasıyla \% 3,5 ve \% 28,4 oranında dayanım kazanılmıştır. Ayrıca, Şekil 5, aktivatör tipinin kazanılan dayanım oranlarına ciddi bir etkisi olduğunu göstermektedir. Şöyle ki, $\mathrm{Na}_{2} \mathrm{SiO}_{3}$ ile aktive edilen tüm örnekler (ham madde tipinden bağımsız olarak), 28 günlük nihai dayanımlarının \% 85'den fazlasını ilk 7 gün içerisinde almışlardır. $\mathrm{Bu}$ değer, $\mathrm{NaOH}$ ile aktive edilen numune gruplarında ise maksimum $\% 71,2$ oranında vuku bulmuştur.

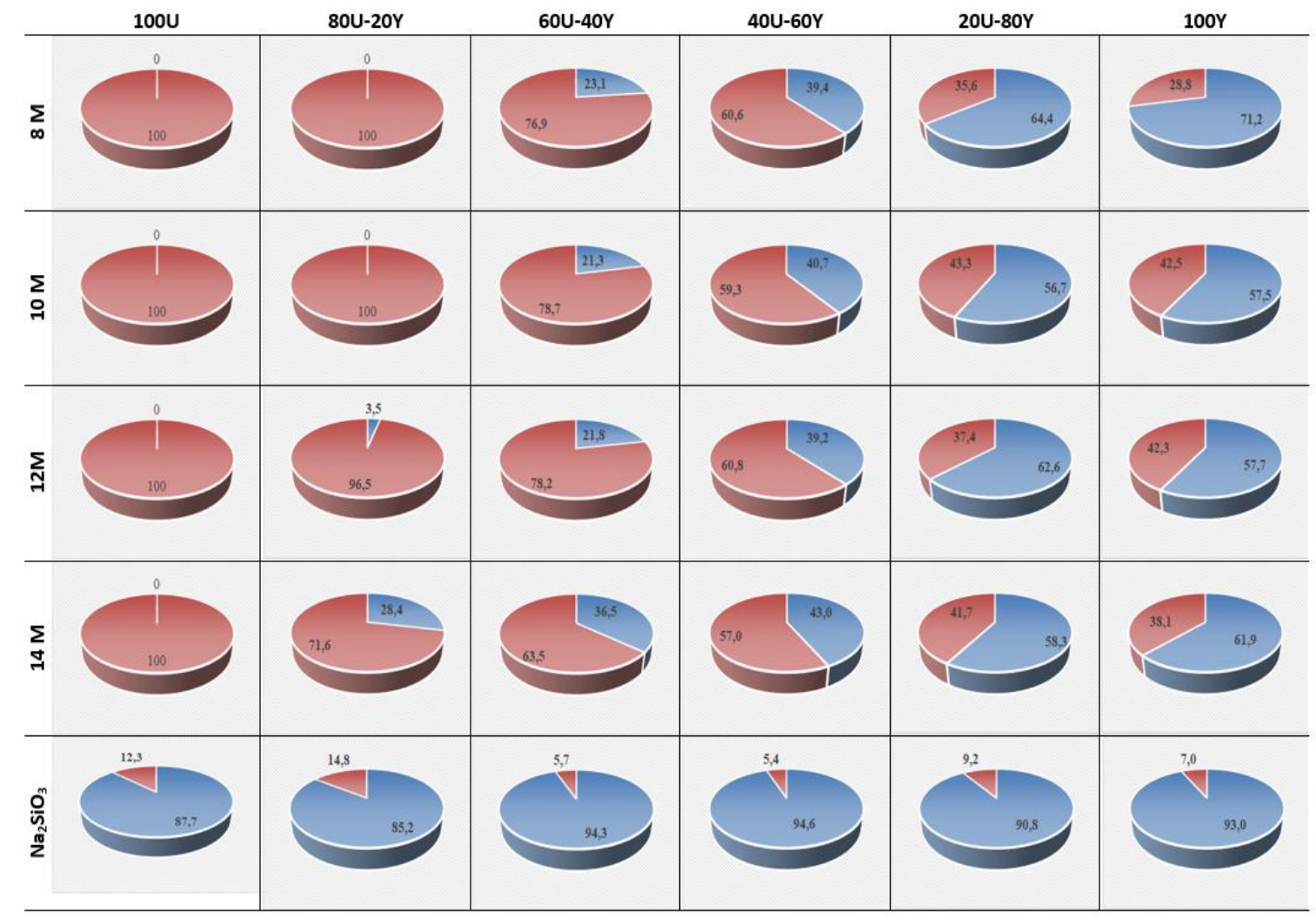

0 - 7 Gün

$7-28$ Gün

Şekil 6. Numune yaşının basınç dayanımı kazanma oranına etkisi 


\section{Sonuç}

Geopolimer hamur örneklerin basınç dayanımlarına farklı ham madde ve aktivatör özelliklerinin incelendiği bu çalışmada elde edilen bulgular aşağıda sıralanmıştır;

1. Ham madde olarak $\% 100$ uçucu kül kullanılan geopolimer hamur numuneleri, $\mathrm{NaOH}$ ile aktive edilmesi halinde ilk 7 günde herhangi bir dayanım kazanamamıştır. Ancak, \%100 uçucu kül numunesinin $\mathrm{Na}_{2} \mathrm{SiO}_{3}$ ile aktive edilmesi sonucunda, 28 günlük basınç dayanımının yaklaşık \%88'i ilk 7 günde kazanılmıştır. Bu durum, F sınıfı uçucu kül kullanılarak üretilecek ve laboratuvar koşullarında kür edilecek geopolimer hamur örneklerinde erken dayanım kazanmak için $\mathrm{Na}_{2} \mathrm{SiO}_{3}$ kullanımının gerekli olduğunu göstermektedir.

2. $100 \mathrm{U}$ ve $80 \mathrm{U}-20 \mathrm{U}$ numuneleri için optimum $\mathrm{NaOH}$ konsantrasyonu $8 \mathrm{M}$ iken, 60U-40Y ve 40U-60Y örneklerinde optimum $\mathrm{NaOH}$ konsantrasyonu $14 \mathrm{M}$, $20 \mathrm{U}-80 \mathrm{Y}$ ve $100 \mathrm{Y}$ numunelerinde ise optimum $\mathrm{NaOH}$ konsantrasyonu $12 \mathrm{M}$ olarak belirlenmiştir. Bu durum, optimum aktivatör konsantrasyonunun kullanılan ham maddenin kimyasal kompozisyonuna bağlı olarak değişiklik gösterdiği sonucunu ortaya çıkarmıştır.

3. Sonuçlar, YFC ikame oranının artmasıyla birlikte geopolimer hamur numunelerinin 7 ve 28 günlük basınç dayanımlarında ciddi artışlar meydana geldiğini göstermektedir.

4. Aktivatör tipinin kazanılan dayanım oranlarına ciddi bir etkisi olduğu gözlenmiştir. Şöyle ki, $\mathrm{Na}_{2} \mathrm{SiO}_{3}$ ile aktive edilen tüm örnekler (ham madde tipinden bağımsız olarak), 28 günlük nihai dayanımlarının \% 85'den fazlasını ilk 7 gün içerisinde almışlardır. Bu değer, $\mathrm{NaOH}$ ile aktive edilen numune gruplarında ise maksimum \% 71,2 oranında vuku bulmuştur.

\section{Kaynakça}

[1] U.S. Geological Survey (USGS), Mineral Commodity Summaries, Feb. 2014.

[2] Amran, Y. M., Alyousef, R., Alabduljabbar, H., \& ElZeadani, M. (2020). Clean production and properties of geopolymer concrete; A review. Journal of Cleaner Production, 251, 119679.

[3] Mehta, P. K., Monterio, P. J. M. (2006a). Concrete: Microstructure, Properties, and Materials, California, USA, 299$301 \mathrm{p}$.

[4] Pacheco-Torgal, F., Cabeza, L. F., Labrincha, J., \& De Magalhaes, A. G. (2014). Eco-efficient construction and building materials: life cycle assessment (LCA), eco-labelling and case studies. woodhead Publishing.

[5] Marinković, S. B. (2013). Life cycle assessment (LCA) aspects of concrete. In Eco-efficient concrete (pp. 45-80). Woodhead Publishing.

[6] Ženíšek, M., Pavlů, T., Fořtová, K., \& Pazderka, J. (2020, February). Use of concrete dust as a partial cement replacement. In AIP Conference Proceedings (Vol. 2210, No. 1, p. 020019). AIP Publishing LLC.

[7] Shalini, A., Gurunarayanan, G., \& Sakthivel, S. (2016). Performance of rice husk ash in geopolymer concrete. Int $\mathbf{J}$ Innov Res Sci Tech, 2, 73-77.

[8] https://www.asbcert.com.tr/bilgi-bankasi/makaleler/sera-gazietkisi-nedir/

e-ISSN: 2148-2683
B. K., \& Mohanty, A. N. (2016). A mix design procedure for geopolymer concrete with fly ash. Journal of cleaner production, 133, 117-125.

[9] Pavithra, P. E., Reddy, M. S., Dinakar, P., Rao, B. H., Satpathy, B. K., \& Mohanty, A. N. (2016). A mix design procedure for geopolymer concrete with fly ash. Journal of cleaner production, 133, 117-125.

[10] Ekinci, E., Türkmen, İ., Kantarci, F., \& Karakoç, M. B. (2019). The improvement of mechanical, physical and durability characteristics of volcanic tuff based geopolymer concrete by using nano silica, micro silica and Styrene-Butadiene Latex additives at different ratios. Construction and Building Materials, 201, 257-267.

[11] Li, N., Shi, C., Zhang, Z., Wang, H., \& Liu, Y. (2019). A review on mixture design methods for geopolymer concrete. Composites Part B: Engineering, 178, 107490.

[12] Reddy, M. S., Dinakar, P., Rao, B. H. (2016). A review of the influence of source material's oxide composition on the compressive strength of geopolymer concrete. Microporous and Mesoporous Materials. 234, 12-23.

[13] Gao, K., Lin, K. L., Wang, D., Hwang, C. L., Tuan, B. L. A., Shiu, H. S., \& Cheng, T. W. (2013). Effect of nano-SiO2 on the alkali-activated characteristics of metakaolin-based geopolymers. Construction and building materials, 48, 441-447.

[14] Davidovits, J. (1999). Chemistry of Geopolymeric systems, terminology. in "GÉOPOLYMÈRE '99 international conference”, J. Geopolymer Institute, Saint-Quentin, France. France, 9, 40.

[15] Van Jaarsveld, J. G. S., Van Deventer, J. S. J., \& Lukey, G. C. (2002). The effect of composition and temperature on the properties of fly ash-and kaolinite-based geopolymers. Chemical Engineering Journal, 89(1-3), 63-73.

[16] Yuan, J., He, P., Jia, D., Yang, C., Yan, S., Yang, Z., ... \& Zhou, Y. (2016). Effect of curing temperature and $\mathrm{SiO}_{2} / \mathrm{K}_{2} \mathrm{O}$ molar ratio on the performance of metakaolin-based geopolymers. Ceramics International, 42(14), 16184-16190.

[17] Sarıcı T. (2019). Puzolan ile güçlendirilmiş inşaat ve yıkıntı atıklarının granüler dolgu olarak kullanılabilirliğinin değerlendirilmesi, (Doktora Tezi, İnönü Üniversitesi Fen Bilimleri Enstitüsü)

[18] Rajarajeswari, A., \& Dhinakaran, G. (2016). Compressive strength of GGBFS based GPC under thermal curing. Construction and Building Materials, 126, 552-559.

[19] Yadollahi, M. M., Benli, A., \& Demirboğa, R. (2015). The effects of silica modulus and aging on compressive strength of pumice-based geopolymer composites. Construction and Building Materials, 94, 767-774.

[20] Kantarci, F., Türkmen, İ., \& Ekinci, E. (2020). Influence of various factors on properties of geopolymer paste: A comparative study. Structural Concrete.

[21] ASTM, C. (2016). Standard test method for compressive strength of hydraulic cement mortars (using 2-in. or [50-mm] cube specimens). Annual Book of ASTM Standards, 4.

[22] Qiu, J., Zhao, Y., Xing, J., \& Sun, X. (2019). Fly ash/blast furnace slag-based geopolymer as a potential binder for mine backfilling: effect of binder type and activator concentration. Advances in Materials Science and Engineering, 2019.

[23] Ahmari, S., \& Zhang, L. (2012). Production of eco-friendly bricks from copper mine tailings through geopolymerization. Construction and building materials, 29, 323-331.

[24] Dong, M., Elchalakani, M., \& Karrech, A. (2020). Development of high strength one-part geopolymer mortar using 
sodium metasilicate. Construction and Building Materials, 236, 117611.

[25] Abhilash, P., Sashidhar, C., \& Reddy, I. R. (2016). Strength properties of Fly ash and GGBS based Geopolymer Concrete. International Journal of ChemTech Research, 9(3), 350-356.

[26] Ravikumar, D., Peethamparan, S., \& Neithalath, N. (2010). Structure and strength of $\mathrm{NaOH}$ activated concretes containing fly ash or GGBFS as the sole binder. Cement and Concrete Composites, 32(6), 399-410.

[27] Bilenler Altundal, M. (2019). Yüksek Fırın Cürufu ve Uçucu Kül Katkılı Geopolimer Betonların\% 5 Sülfürik Asit Etkisinde Mekanik Davranışı (Yüksek Lisans Tezi, İstanbul Gelişim Üniversitesi Fen Bilimleri Enstitüsü) 